\title{
Как правильно подготовить проект печатной платы к производству
}

\author{
О. Баринова ${ }^{1}$
}

УДК 621.3.049.75:658.512.4 | ВАК 05.27.06

\begin{abstract}
Практика показывает, что разработать схему и выполнить трассировку это еще не гарантия успеха. Очень важно правильно подготовить проект печатной платы к передаче производителю, не пропустив ни одной значимой позиции и однозначно описав все особенности и требования к изделию.
\end{abstract}

\section{ВЫБИРАЕМ ПРОИЗВОДИТЕЛЯ}

Первый и самый важный пункт, который желательно обдумать еще на этапе разводки печатной платы (ПП), выбор производства. Это особенно важно в том случае, если плата планируется нестандартная (по структуре, материалам, характеристикам и т. д.) или заведомо будет иметь минимально или максимально допустимые параметры (например, зазор между проводниками, толстые слои меди при узких проводниках и т.д.). В этом случае было бы полезно предварительно обсудить с вашим поставщиком печатных плат планируемые параметры платы и возможность выполнения такого заказа. Это необходимо, чтобы избежать ситуации, когда плата разведена, а изготовить ее либо неожиданно дорого, либо очень долго, либо вообще проблематично

Вообще, надо заметить, что не следует без острой необходимости повсеместно использовать параметры, находящиеся на грани возможностей производителя. Например, самые тонкие проводники и зазоры следует использовать только в тех местах платы, где это реально необходимо, а во всех остальных - стандартные параметры. Не стоит задавать допуск на импеданс $\pm 5 \%$, если достаточно и стандартных $\pm 10 \%$. Используя слишком жесткие параметры, вы сузите круг производителей, которые смогут выполнить ваш заказ, и сделаете продукт дороже. Подробнее о критериях выбора технологических параметров см. [1].

Еще один момент: существует разница между изготовлением прототипов и серийным производством. Не всегда параметры, которые легко обеспечить при маленьком количестве плат, можно так

ООО «ПСБ технологии, СПб», директор,

olga@pcbtech.ru. структурой - 0,75\%) же успешно гарантировать при заказе крупных партий. Поэтому, если планируется, что проект уйдет в серию, то лучше предупредить об этом производителя и согласовать возможные варианты размещения заказа заранее. Может быть, где-то надо сразу упростить проект или договориться о том, что при заказе образцов будет использован один завод, а при заказе серии - другой

Итак, выполнили трассировку, проект печатной платы готов, производитель выбран. Отправляем заказ в изготовление?

Рано! Давайте еще раз проверим основные моменты и убедимся, что заказ оформлен правильно.

\section{ПРОВЕДЕМ ОКОНЧАТЕЛЬНУЮ ПРОВЕРКУ DRC}

DRC - это проверка на соответствие принципиальной схеме и соблюдение допустимых технологических зазоров. При внесении изменений в проект в процессе его разработки, возможно, какие-то элементы переместили, разорвали цепи или произвели другие действия, которые могли привести к ошибочным соединениям,

\begin{tabular}{|c|c|c|c|}
\hline Layer & Info & & Thickness \\
\hline \multirow[t]{2}{*}{ TOP } & $=================0$ & $===============$ & $0.50 z$ \\
\hline & Core R04003C & 0.203 & $8.000(\mathrm{mil})$ \\
\hline \multirow[t]{2}{*}{ L2 } & 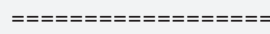 & $===============$ & $0.50 z$ \\
\hline & PP $\quad$ R04450F & $\mathrm{RO} 4450 \mathrm{~F} * 2$ & $8.000(\mathrm{mil})$ \\
\hline \multirow[t]{2}{*}{ L3 } & $=================$ & $===============$ & $0.50 z$ \\
\hline & Core R04003C & 0.203 & $8.000(\mathrm{mil})$ \\
\hline \multirow[t]{3}{*}{ Вот } & $=================0$ & $===============$ & $0.50 z$ \\
\hline & $\mathrm{PP} \quad \mathrm{R} 04450 \mathrm{~F}$ & $\mathrm{RO} 4450 \mathrm{~F} * 2$ & $8.000(\mathrm{mil})$ \\
\hline & R04003C & 0.81 & $31.889(\mathrm{mil})$ \\
\hline
\end{tabular}

Рис. 1. Пример нестандартной несимметричной структуры ПП: на нижнюю сторону платы прессуется сравнительно толстая диэлектрическая пластина. При изготовлении на заводе со средними возможностями и ценами коробление будет около 1,5-2\% (норма для плат с симметричной 
"повисшим» цепям и т.д. Может быть, вы отключали некоторые проверки, чтобы ускорить работу САПР во время трассировки, и таким образом некоторые ошибки остались невыявленными. В любом случае, лишней финальная проверка DRC точно не будет.

\section{ОЦЕНИМ РАЗМЕЩЕНИЕ ПОЛИГОНОВ}

Очень часто разработчики размещают полигоны вплотную к контуру платы. Если не требуется металлизация торцов и плата не для СВЧ-применения, то лучше этого не делать и обеспечить зазор минимум 0,3-0,5 мм от края платы до полигонов. В противном случае в процессе механической обработки платы фреза пойдет прямо по металлу, и возможны заусенцы и шероховатости на медной фольге по краям платы. Есть еще один негативный момент: после фрезеровки на торцах платы будет ничем не защищенная медь, что может вызвать коррозию или замыкания на металлический корпус прибора.

\section{ЕСЛИ НА ПЛАТЕ НУЖНА ТОРЦЕВАЯ МЕТАЛЛИЗАЦИЯ}

Для металлизации торцов необходимо наличие меди на внешних слоях (обязательно на обоих: ТОР и ВОТ) вплотную к контуру платы. Необходимо обеспечить вскрытие маски по контуру ПП в местах торцевой металлизации на обоих внешних слоях минимум на 0,5 мм.

Также надо иметь ввиду, что при торцевой металлизации для закрепления платы на заготовке будут использованы технологические перемычки. Их размер и расположение зависят от правил, принятых на конкретном производстве; обычно применяются перемычки шириной примерно 5 мм при расстоянии между ними порядка 100 мм. Те отрезки торцов ПП, где находились эти перемычки, останутся без торцевой металлизации. Поэтому, если есть критичные участки металлизации, то лучше сразу указать в бланке заказа или прилагаемом чертеже, где можно ставить эти перемычки, а где нежелательно.

\section{ПРОВОДНИКИ И ОТВЕРСТИЯ ВО ВНУТРЕННИХ СЛОЯХ}

Наиболее важная проверка - это контроль расстояния от меди до края отверстия (hole-line space) во внутренних слоях. Очень часто разработчики считают, что это расстояние может быть равно зазору между проводниками, а на самом деле для большинства производств оно не должно быть меньше, чем 0,2 мм. И только для некоторых уникальных заводов, с которыми, например, работает компания «ПСБ технологии", оно может составлять 0,15 мм, а в исключительных случаях, по согласованию и с увеличением стоимости изготовления, $-0,125$.

\section{ОБРАТИМ ВНИМАНИЕ НА ПАЯЛЬНУЮ МАСКУ}

Типичные ошибки:

1. Вскрытие маски, равное размеру контактной площадки.

Любая технологическая установка имеет тот или иной допуск на совмещение, позиционирование, уход инструмента и т. п. При нанесении паяльной маски может произойти незначительное смещение ее рисунка относительно платы, и маска будет частично закрывать контактную площадку. Этого допускать нельзя, поэтому вскрытие маски необходимо делать хотя бы на 0,1 мм больше размера контактной площадки.

2. Вскрытие маски, имеющее размер, намного больший размера площадки.

Оно тоже нежелательно, так как в проекте могут присутствовать элементы с малым шагом, и слишком большое вскрытие маски (более чем на 0,1 мм превышающее размер контактной площадки) чревато тем, что "мостики" маски между площадками или исчезнут совсем, или получатся слишком малой ширины.

В целом, чтобы избежать проблем, для жестких ПП лучше придерживаться "правила 0,1 мм»: маска больше площадки на 0,1мм, и ширина "мостика" маски тоже минимум 0,1 мм. В этом случае большинство производств не будет иметь проблем с нанесением паяльной маски.

\section{ТЕПЕРЬ ПРОВЕРИМ ШЕЛКОГРАФИЮ (МАРКИРОВКУ КРАСКОЙ)}

Перед отправкой в производство визуально осматриваем свой проект. Если символы в проекте плохо читаются, то на готовой плате все будет еще хуже.

Типичные ошибки:

1. Слишком малый размер символов. Для нормальной читаемости на готовой плате высоту символов / текста нужно делать не менее 1 мм.

2. Слишком малая ширина линии. Для нормальной прорисовки ширина апертуры линии должна быть не менее 0,1 мм при нанесении на фольгу толщиной 18 мкм и не менее 0,127 мм при нанесении на фольгу толщиной 35 мкм.

3. Слишком большая ширина апертуры при малой высоте символов. В данном случае текст, позиционные обозначения и т.д. будут плохо читаемы или совсем не читаемы.

4. Надпись попадает на освобожденные от маски контактные площадки. Этого следует избегать, иначе могут возникнуть проблемы при пайке компонентов. С другой стороны, инженер по подготовке к производству может заметить эту опасность, и тогда части символов, которые попадают 
на площадку, будут вырезаны, а на готовой плате останется нечитаемый текст.

5. Цвет надписи совпадает с цветом диэлектрика Обычно такое случается на ВЧ- и СВЧ-платах, для которых не делают покрытия маской, а в требованиях указывают, например, маркировку белой краской, забывая, что собственный цвет подложки (RO4003C/RO4350B, фторопласты и др.) тоже белый. Несложно догадаться, что белое на белом будет плохо читаться, так что в таких случаях лучше выбирать цвет маркировки, который будет четко контрастировать с цветом диэлектрика - например, черный.

\section{БЛАНК ЗАКАЗА}

Итак, самая простая проверка выполнена. Пришла пора приступать к оформлению бланка заказа - это фирменный бланк производителя, в котором отражены все значимые технические параметры печатной платы, допуски, особенности и пр. Бланк заказа обычно можно найти на сайте производителя, а можно заполнить собственный документ; главное - чтобы были отражены все значимые моменты: структура слоев, требования по импедансу, ширина зазоров, проводников, гарантийных поясков, минимальный диаметр отверстия, ну, и, конечно, минимальное расстояние от края просверленного отверстия до меди во внутренних слоях.

Заполненный бланк, во-первых, позволит быстро и наиболее адекватно выполнить оценку вашего заказа и обоснованно выбрать завод, на котором можно его изготовить. Во-вторых, он даст возможность инженеру, который просматривает проект перед отправкой на производство, выполнить дополнительный контроль и согласовать с вами выявленные несоответствия.

\section{ОСНОВНЫЕ ПАРАМЕТРЫ, КОТОРЫЕ НЕОБХОДИМО УКАЗАТЬ ПРИ ОПИСАНИИ ПРОЕКТА ПЕЧАТНОЙ ПЛАТЫ}

Тип платы: жесткая, гибкая, гибко-жесткая. Для гибко-жестких плат и плат с нестандартной структурой необходимо описание слоев или чертеж.

\section{Количество слоев.}

Толщина пП. Обратите внимание, что стандартный допуск на толщину ПП равняется 10\%. Если ваши требования более строги, это необходимо указать.

Размер ПП. Стандартный допуск на обрезку составляет $\pm 0,1 \mathrm{Mм}$.

Минимальные размеры - ширина проводников и зазоров, диаметр отверстия и его контактной площадки (обычно это переходное отверстие), встречающиеся в вашем проекте.
Материал. Некоторые материалы требуют заказа из-за того, что нечасто используются и имеют небольшой срок хранения. Срок поставки может составлять от двух до 12 недель, поэтому, если вы используете нестандартные материалы, заранее задайте поставщику вопрос о наличии материала или сроке его поставки.

структура пП. Приложите чертеж или описание структуры ПП. Если структуры нет, значит, вам важно выдержать указанную толщину ПП, а ее структуру вы оставляете на усмотрение завода.

Глухие и скрытые отверстия. Если таковые имеются, то необходимо полное описание в чертеже или иным способом.

Толщина фольги. Стандартно используется фольга толщиной 18 мкм или 12 мкм, если в проекте есть тонкие (3 mil) проводники и зазоры; стандартная толщина фольги на внутренних слоях - 35 мкм. Нужно помнить, что значение толщины фольги, указываемое для внешних слоев, является начальным - это толщина фольги используемого материала. При изготовлении платы на этапе металлизации отверстий на внешние слои осаждается еще 25-35 мкм меди.

Если слои ПП должны иметь фольгу разной толщины, ее значения обязательно надо написать в бланке заказа или приложить структуру платы отдельным документом. И не забудьте сослаться на него в бланке заказа!

Металлизация торцов и / или пазов. Указать, если требуется, и приложить чертеж или иное описание.

Покрытие площадок. Прописывается требуемый тип финишного покрытия.

Для справки: типичные толщины распространенных финишных покрытий:

- горячее лужение (HASL): 15-25 мкм;

- иммерсионное золочение (ImAu / ENIG): Ni 4-5 мкм, Au 0,05-0,1 мкм;

- иммерсионное олово (ImTin): 10-15 мкм;

- органическое покрытие (OSP/Entek): 20 мкм, при пайке растворяется;

- бессвинцовый HAL: 15-25 мкм.

золочение разъема. Если на плате есть краевой разъем типа ISA, PCI, PCI Express и т. п., то следует указать, требуется ли его золочение, а также приложить чертеж для его обрезки (снятия фаски) или описать фаску в бланке заказа.

Для справки: толщины золотых покрытий разъемов:

- гальваническое золото: Ni 4-5 мкм, Au 0,2-0,5 мкм;

- иммерсионное золото: см. выше.

Импеданс. Если требуется измерение или контроль импеданса, то это необходимо указать, а также дать полное описание (структура платы, значение импеданса, допуск, для каких проводников, опорный слой). 
Давайте поясним. Если в требованиях записано измерение импеданса, то изготовитель печатных плат проводит лишь измерение импеданса (по структуре и параметрам, предложенным заказчиком) после того, как плата изготовлена, и сообщает результат.

При контроле импеданса завод-изготовитель перед запуском плат в производство расчетным путем проверяет, будет ли достигнут заданный импеданс при текущих условиях. Если расчет показывает, что значение импеданса выходит за пределы допуска, то он сообщает заказчику, какой результат будет в реальности, и предлагает на согласование свой вариант - например, изменить структуру ПП или толщины проводников.

Стандартный контроль производится с допуском $\pm 10 \%$.

Отверстия под запрессовку. При наличии таких отверстий следует разместить подробное описание с обязательным указанием допуска на диаметр отверстий или сослаться на прилагаемый чертеж.

Маска и маркировка. Нужно указать, требуются ли маска и маркировка, и уточнить их цвет. По умолчанию: маска - зеленая, маркировка - белая.

Серийный номер. Если на платах нужен серийный номер, то необходимо указать, в каком месте на плате и в каком формате он должен наноситься. По умолчанию серийный номер на платы не ставится.

Другие особенности. Возможно, ваша плата содержит еще какие-то не учтенные выше особенности. обязательно напишите о них.

Сложно? Хлопотно? Но зато можно быть уверенным, что конечный результат - готовая плата - будет именно таким, как вы задумали. На сайте «ПСь технологии" [2] в разделе "Скачать" можно получить бланк, в котором предусмотрены все необходимые поля с подсказками и информацией для выбора возможных параметров. Задача описания проекта станет значительно проще.

\section{ПОСЛЕДНЯЯ ПРОВЕРКА - КОНВЕРТАЦИЯ В САМ-СИСТЕМУ}

Проект проверен, бланк заказа заполнен. Можно сделать еще одну полезную вещь.

Если есть такая возможность, то следует экспортировать проект печатной платы в файлы Gerber и NC-drill и открыть их в САМ-системе, например, САМ350. И проверить, что получилось, в том числе и по всем перечисленным выше параметрам. САМ350 последних версий позволяет проверять все технологические нормы автоматически, нажатием одной кнопки, и выдает список обнаруженных дефектов проекта, причем с ошибкой можно работать не только в редакторе САМ350, но и в связанном с ним через специальный интерфейс редакторе вашей САПР, такой как Cadence OrCAD, Allegro или Mentor Xpedition или PADS.
А можно сразу же не только увидеть, но и исправить эти ошибки прямо в САМ-системе! Это поможет избежать ошибок при конвертации и дальнейшей работе c Gerber-файлами, а если они и будут, то сам разработчик заметит и корректно исправит ихс гораздо более высокой вероятностью, чем фактически посторонний человек - инженер по подготовке к производству на заводе - изготовителе печатных плат.

При конвертации в формат ODB++ или Gerber обратите внимание на следующие моменты.

слои печатной платы. Проверьте, чтобы названия и расширения имени Gerber-файлов совпадали с таковыми в бланке заказа в разделе описания порядка следования слоев. Иногда случается, что расширения могут быть *. СT0, *. PWR, * . GND, а в описании слоев указаны TopLayer, Middle layer1, Middle layer2 и т. п. Может возникнуть путаница, которая приведет к неработоспособности плат.

Сверловка. Многие системы проектирования позволяют настраивать параметры, с которыми будет экспортироваться файл сверловки: разные типы станков, разные единицы измерения, разная точность вывода координат и т.д. Инженеру, готовящему проект к передаче в производство, при импорте файла сверловки в САМ350 необходимо выставить точно такие же параметры, которые были использованы разработчиком при экспорте из CAПP OrCAD, PADS и др. Конечно, грамотный специалист разберется и найдет верную комбинацию, чтобы файл сверловки правильно совместился с файлом слоев, но для избежания казусов желательно прикладывать к бланку заказа или скриншот экрана с параметрами вывода, или отдельный текстовый файл с их списком (например, Excellon 2.4 Inch Leading).

Проверьте правильность экспорта файлов сверловки. Для металлизированных и неметаллизированных отверстий, для каждого типа глухих, скрытых переходных отверстий должны быть разные файлы, при этом их наименование должно соответствовать тому, что приведено в бланке заказа.

В файлах сверловки должны указываться не диаметры сверл, а диаметры отверстий после металлизации.

$$
\therefore *
$$

Вот теперь можно отправлять заказ, не забыв приложить чертежи и прочую документацию, которая описывает технические характеристики, не отраженные в бланке заказа для вашей платы.

\section{ЛИТЕРАТУРА:}

1. "Технологические параметры - критерии выбора". www.pcbtech.ru (раздел «Технологии», подраздел "Технологические возможности по печатным платам»).

2. www.pcbtech.ru. 